\title{
Prevalence of Some Factors Associated to Metabolic Syndrome at Mexico Hospital
}

\author{
Rojas Barahona ${ }^{1}$, Roubier Manuel ${ }^{*}$, Trejos Herrera Marianela ${ }^{1,2}$ \\ ${ }^{1}$ Caja Costarricense de Seguro Social, CENDEISSS, San José, Costa Rica \\ ${ }^{2}$ Caja Costarricense de Seguro Social, Hospital México, San José, Costa Rica \\ Email: rrojashm@ccss.sa.cr, ${ }^{*}$ roubierr@gmail.com, quirós trejos@racsa.co.cr
}

Received 17 June 2015; accepted 31 July 2015; published 3 August 2015

Copyright (C) 2015 by authors and Scientific Research Publishing Inc.

This work is licensed under the Creative Commons Attribution International License (CC BY). http://creativecommons.org/licenses/by/4.0/

(c) $\underset{\mathrm{EY}}{\mathrm{E}}$ Open Access

\begin{abstract}
Objective: To determine associated factors to metabolic syndrome in the populations that participated in the Mexico hospital health fair in February 2007. Materials and Methods: A retrospective, descriptive transverse and analytic study of the population interviewed during the Health Fair held from February 19 to 22. A descriptive analysis was done as well as a single-variable and multivariate analysis of the main variables. Results: San Jose Province reported a higher percentage of cases with $\mathbf{4 0 . 7 \%}$, followed by Heredia with $26.0 \%$ and Alajuela with $24.9 \%$. In the case of Lemon, the percentage was $0.4 \%$ only. Most of the interviewed ones are Costa Ricans, representing $94.0 \%$. The female predominance was notorious with $72.6 \%$. The single-variable and multivariate analysis presented an association among blood pressure, glucose, besides of the body mass index related to the metabolic syndrome. Conclusion: The blood pressure, the glucose, and the body mass index are to be considered as associated factors to metabolic syndrome.
\end{abstract}

\section{Keywords}

Metabolic Syndrome, Blood Hypertension, Glycemia, Mexico Hospital

\section{Introduction}

It is called metabolic syndrome (MS) to the group of metabolic disorders conforming the central distribution obesity, decreasing concentrations of lipoprotein cholesterol united to the high density, elevated levels of triglycerides, increasing blood pressure and the hyperglycemia [1].

The metabolic syndrome is a major public health problem of XXI Century associated with a 5-time increase in the prevalence of type 2 diabetes and 2 - 3 times in cardiovascular disease [1] [2].

Metabolic syndrome is not a new disease; its description took place at least 80 years ago (in the early twenties)

${ }^{*}$ Corresponding author. 
by Kylin, a Swedish physician, who defined the association among hypertension, hyperglycemia and gout [3]. Marañón, the founder of modern endocrinology in Spain, explicitly stated that "hypertension is a prediabetic state; this concept also applies to obesity and there must be some form of general predisposition to diabetes association (in adults) with hypertension so that diet is essential for prevention and treatment of these disorders" [4]. In 1947, Vague published an article which drew attention to the fact that the phenotype of obesity with excessive accumulation of fat in the upper body (android type obesity or male) was associated with metabolic alterations that were observed in type 2 diabetes and cardiovascular disease [5]. Twenty years later, Avogaro et al. documented the simultaneous occurrence of obesity, hyperinsulinemia, hypertriglyceridemia and hypertension [6]. The clinical significance of the metabolic syndrome was highlighted again 20 years later by Reaven [7], who described the existence of a set of metabolic abnormalities, whose central pathophysiological feature was insulin resistance. Reaven called this condition "syndrome X" but, surprisingly, he did not include obesity; however, obesity has been present on the concept of metabolic syndrome in all posterior definitions [8].

Since the first official definition of metabolic syndrome by the Working Group of the World Health Organization (WHO) [8] in August 1999, various definitions have been proposed as alternative. The most accepted ones were elaborated by the European Group for the Study of Insulin Resistance (EGIR) [9] and by the Adult Treatment Panel III (ATP-III) of the National Cholesterol Education Program (NCEP) [10] [11]. In recent years, metabolic syndrome has gained an increasing prominence in the literature and in clinical practice. This syndrome generates a lot of controversy concerning both the definition, to its pathogenesis and, to its clinical utility. The proportion of people who meet diagnostic criteria for metabolic syndrome is high and evolves into a progressive increase in their number. Thus, in the country with the largest number of publications, the United States, the prevalence in large samples such as the NHANES between the years 1988-1994 was around 24.1 percent adjusted to age, among adults 20 or more years and using the ATP-III criteria. These numbers increased significantly in the NHANES 1999-2002, with prevalence among men of 33.7 percent with ATP-III criteria and 39.9 percent with criteria IDF (International Diabetes Federation) and among women by 35.4 and 38.1 percent, respectively [12].

Regarding the prevalence of metabolic syndrome in Spain SIRS (Spanish Insulin Resistance Study) study numbers are 20.8 percent among men and 30.9 percent among women, according to ATP-III criteria [13]. In the study MESYAS [14], 82.4\% of the working populations of 7256 workers in a car factory and some large department stores in Valencia-Spain, with an average age of $45.4 \pm 8.9$ years, were men workers; and the prevalence found was $10.2 \%$.

The modernization of contemporary society has brought an increase in obesity and T2DM, both in developed countries such as those in the process of development [15]. In parallel to the increase in these risk factors, cardiovascular disease mortality (CD), especially coronary ischemic heart disease has increased in Costa Rica in recent decades [16]. Therefore, the aim of the study is to determine the prevalence of factors associated with metabolic syndrome in people interviewed in the health fair held at Mexico Hospital.

\section{Materials and Methods}

\subsection{Population}

The sampling scope of the study consisted of interviewed people (from 15 to 83 years old) who attended the health fair at Mexico Hospital during the period from the $19^{\text {th }}$ to $22^{\text {nd }}$ of February 2007.

\subsubsection{Inclusion Criteria}

People who attended the health fair at Mexico Hospital during the period of time the study was conducted. There was no distinction by age, ethnicity or geographical region.

\subsubsection{Exclusion Criteria}

People with any medical condition confirmed previously to the study, also incomplete and unverifiable data in the records of the collection forms.

\subsection{Sample Size and Sampling Design}

A retrospective, transversal, descriptive and analytical study design was implemented. The sample size was obtained using the formula suggested by Rothman (1986) [17]. Accordingly, it required a minimum of 90 patients; 
however, it was possible to obtain a total of 285 patients which increased the power of the study.

\subsection{Data}

\subsubsection{Source}

The data correspond to the records of those people interviewed in the hospital during the study period.

The information was used in the strictest confidentiality to safeguard the privacy of patients. The interviewed population authorized the gathering and analysis of such data.

\subsubsection{Editing and Reduction}

Data were reviewed to avoid typing errors or lost data and, at the same time the appropriate format for the variables was established; so that the hypothesis test was permitted by convenient methods; thus, the discrete variables were coded increasingly in regards to risk. The same criterion was applied to continuous variables by turning them into dichotomous or polytomous.

It was classified as a possible factor associated with MS to those patients who met at least 2 criteria of the International Diabetes Federation (FID) [11].

This definition emphasizes the importance of central obesity. To define a person as carrying SM must submit:

- Diameter of abdominal circumference $>94$ in men and $>80$ in women or BMI $>30$ and more than 2 of the following criteria;

- Total TG $>150 \mathrm{mg} / \mathrm{dL}$ or being on treatment;

- HDL cholesterol $<40 \mathrm{mg} / \mathrm{dL}$ in men and $<50$ in women or being on treatment;

- BP > 130/85 mmHg or being on treatment;

- Blood glucose $>110 \mathrm{mg} / \mathrm{dl}$ or a diagnosis of type 2 diabetes.

It was created a database in Epi Info 2005 (CDC, 2005) [18] with the information obtained from the selected population. The data was edited and revised by using descriptive statistics and using tests of normality, tests for trend (biological gradient) and the extreme or implausible data were removed.

\subsubsection{Analysis}

1) Descriptive statistics

The description of respondents included in this study was carried out by using frequency measurements with their respective confidence intervals for each stratum.

2) Single-variable analysis

A single-variable analysis was performed in an early stage of the study by using tables $2 \times \mathrm{k}$, through which it was calculated the magnitude and direction of association between the event factors associated with SM with each independent variable via the odds ratios (Odds Ratio). Additionally the fraction attributable to each variable was calculated.

\section{3) Multivariate analysis}

They were included the variables that under the single-variable analysis had value $p \leq 0.25$. It was followed a step by step reverse modeling strategy, based on the $p$ value of the likelihood ratio test [19]. Both analyzes (single-variable and multivariate) were performed using the program EGRET $^{\circledR}$ [20].

\section{Results}

\subsection{Descriptive Analysis}

San Jose Province had the highest percentage of participants with $40.7 \%$, followed by $26.0 \%$ Heredia and Alajuela with $24.9 \%$, while the province of Limon contributed only $0.4 \%$. Most respondents are Costa Rican with $94.0 \%$ also females predominated with $72.6 \%$.

In this table it is also presented the percentages of marital status and age groups with their respective confidence intervals as shown in (Table 1 ).

Table 2 shows the history of Diabetes Mellitus and Hypertension with their percentages, also the percenttages of respondents with blood pressure, body mass index and glucose with their respective confidence intervals. 
Table1. Distribution of participants at Mexico Hospital who were included in the study to determine risk factors associated to metabolic syndrome, (Health Fair February 19 to 22, 2007), according to province, nationality, sex, marital status and age.

\begin{tabular}{|c|c|c|c|c|}
\hline \multirow{2}{*}{ Variable } & \multirow{2}{*}{ Level of variable } & \multicolumn{3}{|c|}{ Interviewees (285) } \\
\hline & & $\mathrm{n}$ & $\%$ & IC 95\% \\
\hline \multirow[t]{7}{*}{ Province } & San José & 116 & 40.7 & $34.9-46.7$ \\
\hline & Heredia & 74 & 26.0 & $21.0-31.5$ \\
\hline & Alajuela & 71 & 24.9 & $20.0-30.4$ \\
\hline & Cartago & 9 & 3.2 & $1.5-5.9$ \\
\hline & Guanacaste & 8 & 2.8 & $1.2-5.5$ \\
\hline & Puntarenas & 6 & 2.0 & $0.6-4.0$ \\
\hline & Limón & 1 & 0.4 & $0-1.9$ \\
\hline \multirow[t]{4}{*}{ Nationality } & Costa Rican & 268 & 94.0 & $90.6-96.5$ \\
\hline & Nicaraguan & 15 & 5.2 & $3.0-8.6$ \\
\hline & Swedish & 1 & 0.4 & $0-1.9$ \\
\hline & Venezuelan & 1 & 0.4 & $0-1.9$ \\
\hline \multirow[t]{2}{*}{ Sex } & Female & 207 & 72.6 & $67.0-77.7$ \\
\hline & Male & 78 & 27.4 & $22.3-32.9$ \\
\hline \multirow[t]{6}{*}{ Marital status } & Married & 155 & 54.4 & $48.4-60.3$ \\
\hline & Single & 75 & 26.3 & $21.3-31.8$ \\
\hline & Divorced & 27 & 9.5 & $6.3-13.5$ \\
\hline & Widow & 14 & 5.0 & $2.5-9.6$ \\
\hline & Free Union & 11 & 3.9 & $1.6-8.4$ \\
\hline & Separated & 3 & 1.1 & $0.2-3.0$ \\
\hline \multirow[t]{4}{*}{ Age } & $15-25$ & 23 & 8.1 & $5.2-11.9$ \\
\hline & $26-45$ & 98 & 34.4 & $28.9-40.2$ \\
\hline & $46-65$ & 139 & 48.8 & $42.8-54.7$ \\
\hline & $>65$ & 25 & 8.8 & $5.8-12.7$ \\
\hline
\end{tabular}

Table 2. Distribution of participants at Mexico Hospital who were included in the study to determine risk factors associated to metabolic syndrome, (Health Fair February 19 to 22, 2007), According to history of diabetes mellitus, antecedents of blood hypertension and body mass index.

\begin{tabular}{ccccc}
\hline \multirow{2}{*}{ Variable } & Level of variable & \multicolumn{3}{c}{ Interviewees (285) } \\
\cline { 3 - 4 } Antecedents of diabetes mellitus & Yes & $\mathrm{n}$ & $\%$ & $55 \%$ \\
\hline Antecedents of blood hypertension & No & 175 & 61.4 & $32.9-44.5$ \\
& Yes & 110 & 38.6 & $60.5-71.8$ \\
Blood pressure & No & 189 & 66.3 & $28.2-39.5$ \\
Body mass index & Normal & 96 & 33.7 & $57.6-69.1$ \\
Glycemia & Pathological & 181 & 63.5 & $30.9-42.4$ \\
& Normal & 104 & 36.5 & $50.2-62.0$ \\
& Pathological & 160 & 56.1 & $38.0-49.2$ \\
\hline
\end{tabular}




\subsection{Single-Variable Analysis}

It was determined in the single-variable analysis (Table 3 ) that the antecedents of diabetes mellitus, arterial hypertension is not a factor that significantly influences relating to SM $(p>0.05)$; it also showed that categorized age was indeed associated significantly ( based on $\alpha$ value of 0.05 ) with the SM based on the age group of 46 - 65 years (OR: 8.7, 95\% CI 1.9 - 38.5, $p<0.01$ ), also in those $>65$ years (OR : 15.7, 95\% CI $3.0-82.5, p<$ $0.01)$.

Moreover it showed that body mass index (OR: 5.4, 95\% CI $3.2-9.0, p<0.01$ ), besides blood pressure (OR: 27.5, 95\% CI 14.3 - 52.6, $p<0.01$ ) and glucose levels (OR: 8.0, 95\% CI $4.2-15.2, p<0.01$ ) actually can be significantly associated with MS.

The fraction attributable to the factors associated with MS by the abnormal increase in blood pressure was $65 \%$, indicating that the proportion of respondents could be preventing the SM if their blood pressure were normal.

\subsection{Multivariate Analysis}

This analysis reaffirmed the findings of the single-variable analysis, so that histories of diabetes mellitus, hypertension besides the age of patients are not risk factors for MS.

Moreover it showed that body mass index (OR: 20.3, 95\% CI $7.2-57.4, p<0.01$ ), plus levels of glucose (OR: 30.0, 95\% CI 9.0 - 95.1, $p<0.01$ ) and blood pressure (OR: 103.7, 95\% CI 33.0 - 325.2, $p<0.01$ ) may indeed be associated significantly with the SM respectively (Table 4).

Table 3. Single-variable analysis of factors associated to metabolic syndrome, (Health Fair February 19 to 22, 2007).

\begin{tabular}{|c|c|c|c|c|c|}
\hline Variable & Level of variable & OR & Interval reliability 95\% & Fraction attributable & $p$ \\
\hline \multirow[t]{4}{*}{ Age } & $15-25=0$ & 1.0 & & & \\
\hline & $26-45=1$ & 4.2 & $0.9-19.1$ & 0.45 & 0.05 \\
\hline & $46-65=2$ & 8.7 & $1.9-38.5$ & 0.78 & $<0.01$ \\
\hline & $>66=3$ & 15.7 & $3.0-82.5$ & 0.75 & $<0.01$ \\
\hline Antecedents of diabetes mellitus & $\begin{array}{l}\text { No }=0 \\
\text { Yes }=1\end{array}$ & $\begin{array}{l}1.0 \\
0.9\end{array}$ & $0.5-1.5$ & 0.08 & 0.37 \\
\hline Antecedents of blood pressure & $\begin{array}{l}\text { No }=0 \\
\text { Yes }=1\end{array}$ & $\begin{array}{l}1.0 \\
0.7\end{array}$ & $0.4-1.2$ & 0.10 & 0.12 \\
\hline Body mass index & $\begin{array}{l}\text { No }=0 \\
\text { Yes }=1\end{array}$ & $\begin{array}{l}1.0 \\
5.4\end{array}$ & $3.2-9.0$ & 0.44 & $<0.01$ \\
\hline Blood pressure & $\begin{array}{l}\text { No }=0 \\
\text { Yes }=1\end{array}$ & $\begin{array}{c}1.0 \\
27.5\end{array}$ & $14.3-52.6$ & 0.65 & $<0.01$ \\
\hline Glycemia & $\begin{array}{l}\text { No }=0 \\
\text { Yes }=1\end{array}$ & $\begin{array}{l}1.0 \\
8.0\end{array}$ & $4.2-15.2$ & 0.28 & $<0.01$ \\
\hline
\end{tabular}

Table 4. Multivariate analysis of factors associated to metabolic syndrome, studied at Mexico Hospital, (Health Fair 19 to 22 February, 2007).

\begin{tabular}{|c|c|c|c|}
\hline Variable & OR & Interval of reliability $95 \%$ & $p$ \\
\hline Age & 1.1 & $0.6-2.0$ & 0.71 \\
\hline BMI & 20.3 & $7.2-57.4$ & $<0.01$ \\
\hline Glycemia & 30.0 & $9.0-95.1$ & $<0.01$ \\
\hline Blood pressure & 103.7 & $33.0-325.2$ & $<0.01$ \\
\hline Antecedents DM & 1.1 & $0.4-3.3$ & 0.79 \\
\hline Antecedents BHT & 0.7 & $0.2-2.0$ & 0.47 \\
\hline
\end{tabular}

BMI: Body Mass Index; DM: Diabetes Mellitus; BHT: Blood Hyper Tension. 


\section{Discussion}

Understanding the metabolic syndrome is essential to allow the detection of people with high risk of disease. From an epidemiological perspective, metabolic syndrome confirms the relationship between conditions associated with lifestyle (obesity, cholesterol, increased blood pressure, insulin resistance, hyperglycemia, etc.). People with metabolic syndrome have a greater risk which doubles the likelihood of having a heart attack compared with other people without the syndrome [21]. Knowledge of the factors associated with this syndrome can help reduce the number of these events and their side effects, not only for the patient and relatives but for the overall health system. This study determined the prevalence of some factors associated with the syndrome. While not all of the factors associated with MS were analyzed due to lack of certain determinations, the results are revealing in the fact that it could be demonstrated the presence of some of these factors in the population studied. Factors such as obesity (BMI), blood pressure and blood sugar levels have a strong association with MS. Obesity is one of the most important metabolic alterations worldwide which is the cause of major health impacts as well as being the most important nutritional problem in the developed world, because $10 \%$ of such population is obese [22]. This condition affects all ages and sexes and is associated with the emergence of a number of diseases that are in the top place in the tables of morbidity and mortality of the population, as are ischemic heart disease, hypertension, diabetes mellitus type 2, brain stroke and some cancers surpassing its incidence relative to subjects with normal weight [23]. Recent studies indicate the role of glucose in blood pressure control. It has been demonstrated that it raises blood pressure in the presence of endothelial dysfunction and that the glucose values above the normal range are associated with increased cardiovascular mortality [24].

\section{Conclusions and Recommendation}

The changes in healthy lifestyle are recommended for the treatment of MS initial therapy. It is effective, multifactorial and individualized management of various factors that define, reducing the risk of cardiovascular disease. Not enough to deal separately with each component of the syndrome, it is necessary to try to stop their origin: resistance to insulin. It is essential to establish and maintain a healthy lifestyle through proper diet and regular physical exercise to achieve the ideal weight. The findings and conclusions of this investigation as well as others, agree on the importance of early detection of risk factors associated with MS through preventive health programs that are oriented in periodic determinations of blood glucose, blood pressure, obesity, as well as dyslipidemia and microalbuminuria. This study opens to the thoughts of other investigators to continue the research of others factors that can contribute in the metabolic syndrome.

The empowerment of the heath policies in the matter of prevention of metabolic syndrome in the Costa Rica's territory, can be done by the use of different strategies like health fairs, prevention programs and community education.

\section{Acknowledgements}

Deeply thank the organizing committee of the Health Fair and the organizing subcommittee, as well as commercial firms, university students in nutrition, medicine, laboratory technicians and nurses who participated in this activity, without which there was no It has been possible to make determinations and collect information for this study was conducted. Thank you very much for your effort and dedication.

\section{References}

[1] Eckel, R.H., Grundy, S.M. and Zimmet, P.Z. (2005) The Metabolic Syndrome. Lancet, 365, 1415-1428. http://dx.doi.org/10.1016/S0140-6736(05)66378-7

[2] Zimmet, P., Alberti, K.G. and Shaw, J. (2001) Global and Societal Implications of the Diabetes Epidemic. Nature, 414, 782. http://dx.doi.org/10.1038/414782a

[3] Zimmet, P., Alberti, G. and Shaw, J.E. (2005) Mainstreaming the Metabolic Syndrome: A Definitive Definition. Editorial. Medical Journal of Australia, 183, 175-176.

[4] Marañón, G. (1927) Prädiabetische Zustände. Abhandlungen aus den grenzgebiete der Inneren Secretion. Wisenschafthliche Verlags Buchhandlung Rudolf Novak. 8 Co. Leipzig, Budapest, 12-42.

[5] Vague, J. (1947) Sexual Differentiation, a Factor Affecting the Forms of Obesity. La Presse Médicale, 30, $339-340$.

[6] Avogaro, P., Crepaldi, G., Enzi, G. and Tiengo, A. (1967) Associazione di iperlipidemia, diabete mellito e obesità di 
medio grado. Acta Diabetologica Latina, 4, 36-41. http://dx.doi.org/10.1007/BF01544100

[7] Reaven, G. (1988) Role of Insulin Resistance in Human Disease. Diabetes, 37, 1595-1607. http://dx.doi.org/10.2337/diab.37.12.1595

[8] World Health Organization (1999) Definition, Diagnosis and Classification of Diabetes Mellitus and Its Complications. Report of a WHO Consultation. WHO, Geneva.

[9] Balkau, B. and Charles, M.A. (1999) Comment on the Provisional Report from the WHO Consultation. European Group for the Study of Insulin Resistance (EGIR). Diabetic Medicine, 16, 442-443. http://dx.doi.org/10.1046/j.1464-5491.1999.00059.x

[10] (2001) Executive Summary of the Third Report of the National Cholesterol Education Program (NCEP) Expert Panel on Detection, Evaluation, and Treatment of High Blood Cholesterol in Adults (Adult Treatment Panel III). JAMA, 285, 2486-2482. http://dx.doi.org/10.1001/jama.285.19.2486

[11] International Diabetes Federation (2005) The IDF Consensus Worldwide Definition of the Metabolic Syndrome. http://www.idf.org/webdata/docs/MetSyndrome_FINAL.pdf

[12] Ford, E.S., Li, C., Imperatore, G. and Cook, S. (2006) Age, Sex, and Ethnic Variations in Serum Insulin Concentrations among U.S. Youth: Findings from the National Health and Nutrition Examination Survey 1999-2002. Diabetes Care, 29, 2605-2611. http://dx.doi.org/10.2337/dc06-1083

[13] Lorenzo, C., Serrano-Rios, M., Martinez-Larrad, M.T., Gabriel, R., Williams, K., Gomez-Gerique, J.A., et al. (2003) Central Adiposity Determines Prevalence Differences of the Metabolic Syndrome. Obesity Research, 11, 1480-1487. http://dx.doi.org/10.1038/oby.2003.198

[14] Alegria, E., Cordero, A., Laclaustra, M., Grima, A., Leon, M., Casasnovas, J.A., et al. (2005) Prevalence of Metabolic Syndrome in the Spanish Working Population: MESYAS Registry. Revista Española de Cardiología, 58, 797-806. http://dx.doi.org/10.1157/13077231

[15] Grundy, S.M. (2006) Does the Metabolic Syndrome Exist? Diabetes Care, 29, 1689-1692. http://dx.doi.org/10.2337/dc05-2307

[16] Fernández, E. and Ymorera, O. (1997) Síndrome X en Costa Rica diabetes mellitus tipo II, obesidad con estigma dérmico. Revista Medica de Costa Rica y Centroamerica, 538, 35-38.

[17] Rothman, J.K. (1986) Modern Epidemiology. Little, Brown and Company, Boston.

[18] Centers for Diseases Control and Prevention (2005) Epi Info 2005 ${ }^{\mathrm{TM}}$. Manual for Users.

[19] Hosmer, D.W. and Lemeshow, S. (1989) Applied Logistic Regression. Willey \& Sons, Hoboken, 373.

[20] EGRET (1999) Reference Manual: Digital Version.

[21] Isomaa, B., Almgren, P., Tuomi, T., et al. (2001) Cardiovascular Morbidity and Mortality Associated with the Metabolic Syndrome. Diabetes Care, 24, 683-689. http://dx.doi.org/10.2337/diacare.24.4.683

[22] Despes, J.P. (2001) Health Consequences of Visceral Obesity. Annals of Medicine, 3, 534-541. http://dx.doi.org/10.3109/07853890108995963

[23] Adami, G.F. and Ravera, G. (2001) Metabolic Syndrome in Severely Obese Patients. Obesity Surgery, 11, $543-545$. http://dx.doi.org/10.1381/09608920160556977

[24] Cubeddu, L.X. (2002) Insulin Resistance and Upper-Normal Glucose Levels in Hypertension: A Review. Journal of Human Hypertension, 43, 363-379. http://dx.doi.org/10.1038/sj.jhh.1001343 